\title{
Learning from dynamic triggering of low-frequency tremor in subduction zones
}

\author{
Masatoshi Miyazawa' ${ }^{1}$ Emily E. Brodsky², and Jim Mori ${ }^{1}$ \\ ${ }^{1}$ Disaster Prevention Research Institute, Kyoto University, Japan \\ ${ }^{2}$ Department of Earth and Planetary Sciences, University of California, Santa Cruz, California, USA \\ (Received August 18, 2008; Revised October 4, 2008; Accepted October 9, 2008; Online published October 24, 2008)
}

\begin{abstract}
Remote triggering of small low-frequency seismic tremor (non-volcanic tremor) near the seismic-aseismic transition zone of subduction zones, by surface waves from large distant earthquakes, has been reported in southwest Japan and the Cascadia region. Recent observed triggering in southwest Japan from three large earthquakes (2003 Tokachi-oki, 2007 Solomon, and 2008 Wenchuan) covering wide azimuthal information provides strong evidence for the influence of fluids in the source area. The Coulomb failure stress analyses suggest the effective friction coefficient is large for southwest Japan and small for the Cascadia region, which could be related to the amount of fluid in the source regions of the low-frequency tremor.
\end{abstract}

Key words: Dynamic triggering, low-frequency tremor, 2008 Wenchuan earthquake.

\section{Introduction}

Near the seismic-aseismic transition zone of the Nankai subduction zone in southwest Japan, deep low-frequency earthquakes and tremor (non-volcanic tremor) have been observed (e.g., Obara, 2002; Shelly et al., 2006; Nugraha and Mori, 2006). The seismicity increases in association with slow slip events along the plate subduction (e.g., Hirose and Obara, 2005). Similar episodic slip involving tremor has been also observed in the Cascadia subduction zone (e.g., Rogers and Dragert, 2003; Kao et al., 2006; Schwartz and Rokosky, 2007). Both in southwest Japan and the Cascadia region, remote triggering of small lowfrequency seismic tremor at depths of $\sim 30 \mathrm{~km}$ or shallower by surface waves from large distant earthquakes, has been reported in several recent studies (Obara, 2003; Miyazawa and Mori, 2005, 2006; Rubinstein et al., 2007, 2008a; Miyazawa and Brodsky, 2008), and the triggering from earth tides is also found (Rubinstein et al., 2008b; Nakata et al., 2008).

The orientations and types of strains produced by the triggering surface waves contribute information to help clarify the source mechanism of these little understood lowfrequency events. In southwest Japan, Miyazawa and Mori (2006) and Miyazawa and Brodsky (2008) investigated the periodic triggering from the 2003 Tokachi-oki earthquake and the 2004 Sumatra-Andaman earthquake and find that dilatational strain changes and normal stress reduction associated with passage of Rayleigh waves are responsible for the event triggering, which suggests evidence for fluid related events. However, in the Cascadia region, Rubinstein et al. (2007) find that shear stress changes due to Love waves from the 2002 Denali earthquake $\left(M_{\mathrm{w}}=7.9\right)$ triggered the tremor. Although Rubinstein et al. (2008a) report the triggering due to both Love and Rayleigh waves

Copy right(c) The Society of Geomagnetism and Earth, Planetary and Space Sciences (SGEPSS); The Seismological Society of Japan; The Volcanological Society of Japan; The Geodetic Society of Japan; The Japanese Society for Planetary Sciences; TERRAPUB from other large earthquakes, the Rayleigh wave triggering is not so significant as we see in southwest Japan. To elucidate why these differences appear, we examine the recent triggering in southwest Japan from three large earthquakes: 2003 Tokachi-oki $\left(M_{\mathrm{w}}=8.1\right), 2007$ Solomon $\left(M_{\mathrm{w}}=8.1\right)$, and 2008 Wenchuan $\left(M_{\mathrm{w}}=7.9\right)$. These three earthquakes provide a range of geometries that is necessary to distinguish the processes. Should all three show triggering on the Rayleigh waves, then dilatational stresses are a key to the triggering process. If shear triggering is also important, then the differences in the resolved shear stress of the Love and Rayleigh waves from the different earthquakes should be reflected in the triggering phase.

\section{Observation of Triggered Tremor}

Recent observed triggering from three large earthquakes, 2003 Tokachi-oki $\left(M_{\mathrm{w}}=8.1\right), 2007$ Solomon $\left(M_{\mathrm{w}}=8.1\right)$ and 2008 Wenchuan $\left(M_{\mathrm{w}}=7.9\right)$ are shown in Fig. 1. For each event, the top trace is the high-frequency $(4-16 \mathrm{~Hz}) \mathrm{ra}-$ dial component of station KWBH (high sensitivity seismic network) which shows the triggered low-frequency tremor that has dominant frequencies of about $1-10 \mathrm{~Hz}$, and the middle and bottom traces are low-frequency $(0.01-1 \mathrm{~Hz})$ radial (Rayleigh wave) and transverse (Love wave) components, respectively, of station TSA (broadband seismic network). $P$ wave arrivals from the distant earthquakes are clearly observed in the high-frequency component. In the coda of the traces, periodic triggering of low-frequency tremor can be seen. The main result of these observations is that triggered tremor is clearly correlated with both the period and amplitude of the radial component of surface waves (Rayleigh waves), and is not related to the transverse component (Love waves). The triggered tremor is thought to be the result of shear fracture associated with plate subduction (Shelly et al., 2006; Ide et al., 2007; Miyazawa and Brodsky, 2008), and shear triggering should depend on the surface wave polarization. For these three earthquakes, the seismic waves arrive from different directions and Fig. 2 


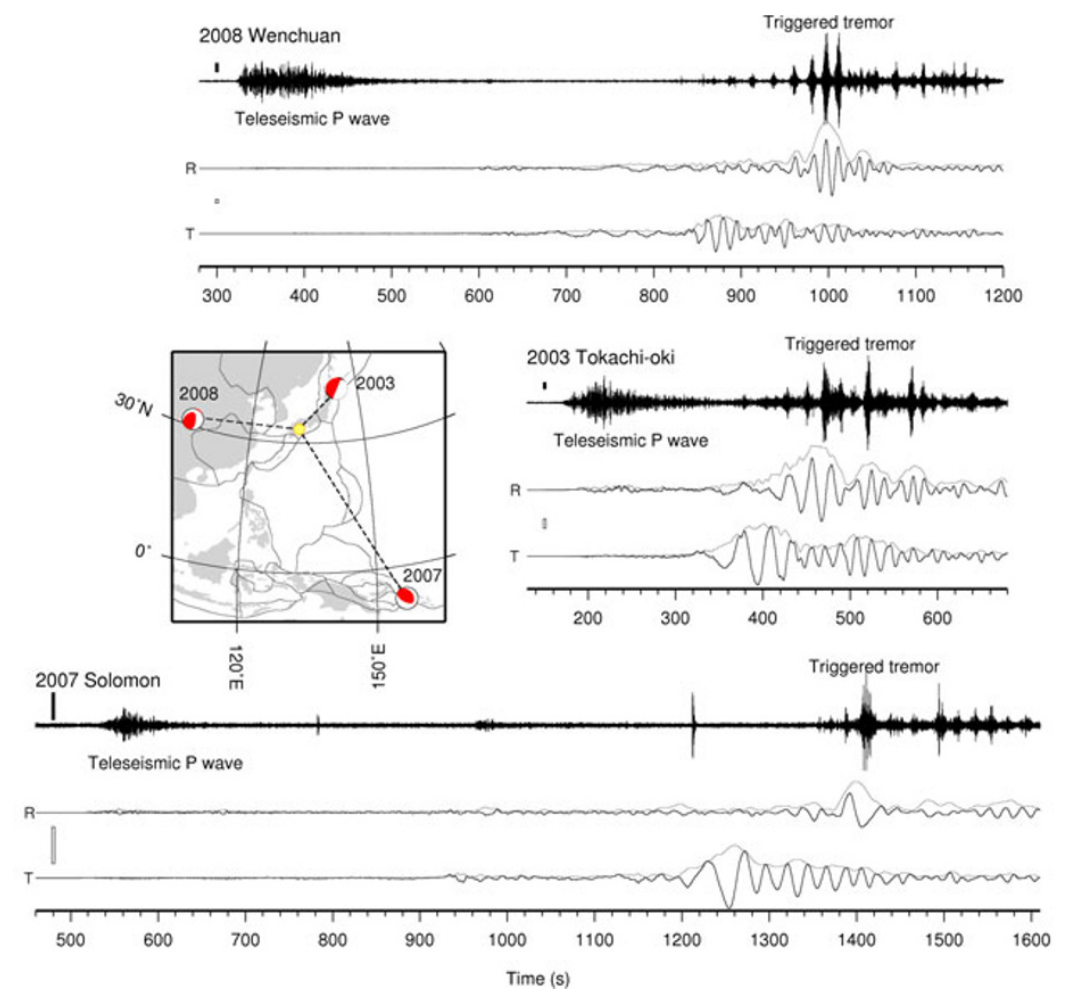

Fig. 1. Three large distant earthquakes (2003 Tokachi-oki, 2007 Solomon, and 2008 Wenchuan) recorded in southwest Japan (yellow circle). Source mechanisms are from the Global CMT catalogue (www.globalcmt.org). For each event, the top trace is the high-frequency (4-16 Hz) radial component of station KWBH (high sensitivity seismic network) which shows the triggered tremor that has the dominant frequency of about 1-10 Hz. The middle and bottom traces are low-frequency $(0.01-1 \mathrm{~Hz}$ ) radial (Rayleigh wave) and transverse (Love wave) components, of station TSA (broadband seismic network). Zero in time is the earthquake origin time. Envelopes (gray lines) of the long period waves are constructed from the radial and vertical components and the transverse component to show the amplitudes of Rayleigh and Love waves, respectively. Solid black and white bars show scales of $0.1 \mu \mathrm{m} / \mathrm{s}$ for the top traces and $1 \mathrm{~mm} / \mathrm{s}$ for the middle and lower traces. The two observation stations and epicenters of tremor are located within $40 \mathrm{~km}$ (Fig. 3). For the 2007 Solomon event, in the high-frequency trace, the teleseismic $P$ wave from an aftershock $(M=6.6)$ is observed at 960-1000 s during arrival of $S$-wave from the mainshock and the single local micro-earthquake is recorded around $1200 \mathrm{~s}$.

shows the shear stress contribution from Love waves resolved on the fault plane. Assuming that the slip direction of triggered tremor is along a southeast direction on the Nankai subduction zone, large shear stress should be produced from Love waves for the 2003 Tokachi-oki and 2008 Wenchuan earthquakes. Even if we assume different slip directions, since the arriving waves from the three earthquakes cover all azimuths, at least one earthquake should have a large shear component consistent with the slip direction. Although some low-level triggering during the Love wave is evident for the 2003 Tokachi-oki and 2008 Wenchuan earthquakes, the dominant triggered response occurs during the Rayleigh waves for all three earthquakes independent of the azimuth of the incoming waves. These observations support our hypothesis that the triggering in southwest Japan is due to dilatational stresses and not due to shear stress changes.

In southwest Japan, volume strain changes which are produced only by Rayleigh waves, are thought to be responsible for the triggering (Miyazawa and Mori, 2006; Miyazawa and Brodsky, 2008). In the source region at depth of about $30 \mathrm{~km}$, amplitude of the tremor exponentially increases with volumetric dilatation produced by Rayleigh waves with periods of $15-30 \mathrm{~s}$.

This relationship is clearly seen in the case of the 2008 Wenchuan earthquake. Figure 3 shows epicenters of deeplow frequency earthquakes (yellow) and triggered tremor

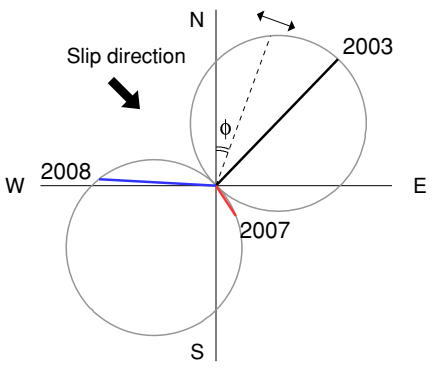

Fig. 2. Shear stress contribution from Love wave resolved on a fault plane as a function of backazimuth. The grey circles indicate the peak value of the dip-parallel shear stress component. We assume the fault slip is along an up-dip direction due to the northwestward subduction (bold arrow) and the incoming Love wave is the same for any backazimuth. For example, when the backazimuth is $\phi$ and the Love wave particle motion is shown by a narrow arrow, the peak value of the resolved shear stress is indicated by the length of a broken line. The values for the 2003 Tokachi-oki, 2007 Solomon, and 2008 Wenchuan earthquakes are shown in black, red, and blue, respectively. The 2003 event has the largest effect and the 2007 event the smallest.

(red). Tremor was located by using a modified envelope correlation method (Obara, 2002; Miyazawa and Mori, 2005). It is observed during arrivals of large amplitude Rayleigh waves and consists of a sequence of three large amplitude events (Figs. 1 and 4(a)). We calculated the strain and stress changes at the source region, associated with 


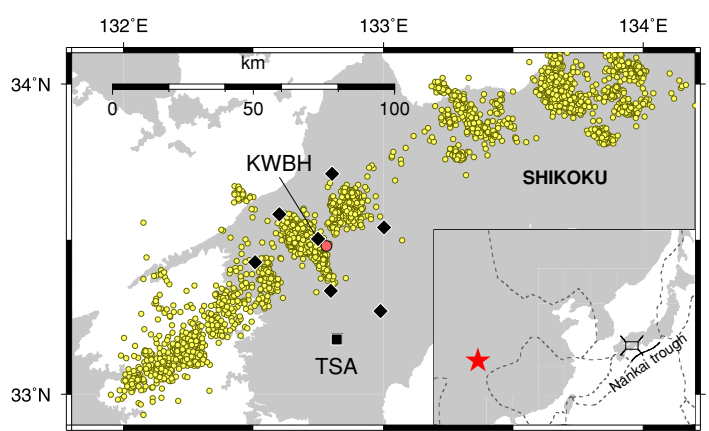

Fig. 3. Epicenters of low-frequency earthquakes from the catalogue of the Japan Meteorological Agency (JMA) (yellow) and triggered tremor (red) in southwest Japan. The depth of the triggered tremor is about $30 \mathrm{~km}$. Inset map shows the location of the 2008 Wenchuan earthquake $\left(M_{\mathrm{w}}=7.9\right)$ (star) and southwest Japan (box). Waveforms observed at KWBH and TSA are shown in Fig. 1. Diamonds are high sensitivity seismic network stations used to locate the triggered tremor.

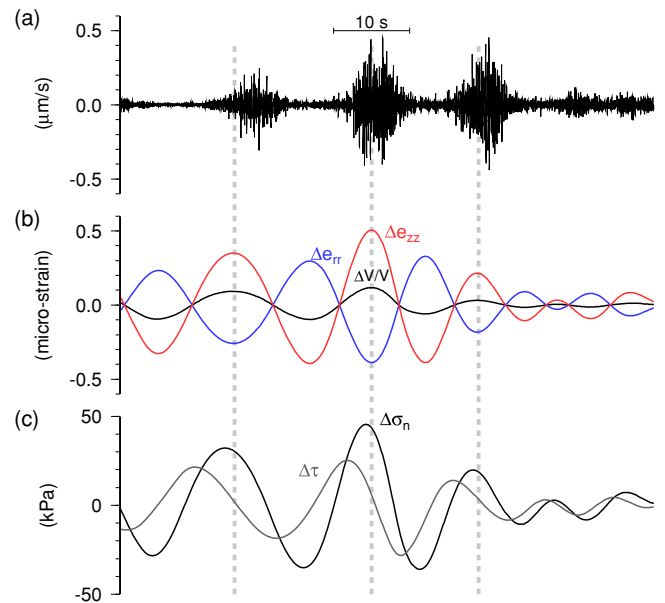

Fig. 4. Relationship between the three large triggered tremor (a), strain changes (b), and stress changes on the reverse fault with a northwestward dip aligned with the subducting slab (c) at the source at depth of $30 \mathrm{~km}$, for the case of the 2008 Wenchuan earthquake. Time is corrected in order to compare these traces. The correction error between tremor trace and strain/stress changes is $\pm 1 \mathrm{~s}$ or possibly more. The strain/stress changes at the source area are obtained by the method of Miyazawa and Brodsky (2008). Vertical dashed line corresponds to the large peak volume expansion. The source mechanism is assumed as (strike, dip, rake $)=(225,10,90)$. The positive stress change is subjected to encourage the plate motion on the plate boundary, i.e. up-dip slip. Large amplitude of the tremor corresponds to both the volume expansion $(\Delta V / V>0)$ with vertical expansion $\left(\Delta e_{z z}>0\right)$ and radial compression $\left(\Delta e_{r r}<0\right)$ and positive normal stress changes $\left(\Delta \sigma_{\mathrm{n}}\right)$. There is poor correlation between the tremor amplitude and the shear stress changes $(\Delta \tau)$.

arrivals of surface waves (Miyazawa and Brodsky, 2008; Hill, 2008), and compared them with the triggered tremor (Fig. 4). The time is corrected to compare these traces, while the error includes \pm 1 s or possibly more due to uncertainties of the source location and $S$ wave velocity model. However, this error is much smaller than the period of surface waves and does not affect the results. Large amplitude tremor corresponds fairly well to the volume expansion $(\Delta V / V>0)$ with vertical expansion $\left(\Delta e_{z z}>0\right)$ and radial compression $\left(\Delta e_{r r}<0\right)$.

Other large earthquakes, such as the 2004 Sumatra $\left(M_{\mathrm{w}}=9.2\right)$ and the 2006 and 2007 Kuril earthquakes
$\left(M_{\mathrm{W}}=8.3\right.$ and 8.1), also produced the periodic triggering of tremor, however due to the complicated structure along the propagation paths which produces complex surface wave trains, it is difficult to clearly distinguish between Rayleigh and Love wave triggering.

\section{Discussion and Conclusion}

These observations in southwest Japan provide strong evidence for the effects of fluids in the source area because fluid can be affected by normal stress changes and not by shear stress changes. On the other hand, these observations differ from the triggering of similar non-volcanic tremor in the Cascadia subduction zone, where shear stress changes from Love waves can also effectively induce the tremor (Rubinstein et al., 2007, 2008a). Although surface wave stress components on a fault plane vary significantly with fault dip (Hill, 2008), the geometries are similar around the tremor source at depth of $\sim 30 \mathrm{~km}$ or shallower, where the dip angles in southwest Japan and the Cascadia region are $\sim 10 \mathrm{deg}$ and $\sim 15 \mathrm{deg}$, respectively. Moreover, the source mechanisms seem to be a result of shear fracture associated with plate subduction. These observations indicate a difference of physical property in the two regions.

The Coulomb failure stress change is used to describe the triggering dynamic stress changes. This optimizes an offset between the shear stress change $(\Delta \tau)$ and normal stress change $\left(\Delta \sigma_{\mathrm{n}}\right)$ through the apparent friction coefficient $(\mu)$ on the fault, i.e. $\Delta \tau+\mu \Delta \sigma_{\mathrm{n}}$. The observed differences in triggering strain (stress) in the two regions suggest that the coefficient of friction is large for southwest Japan and small for the Cascadia region. Figure 5 shows the correlation as a function of the friction coefficient in southwest Japan for the cases of the 2003 Tokachi-oki earthquake and 2008 Wenchuan earthquake together with the correlation in the Cascadia region for the case of the 2002 Denali earthquake. Negative values of $\mu$ are included to illustrate that the physical effect can be modeled only with realistic values of friction. For the 2008 Wenchuan earthquake, the correlation becomes large for a large $\mu$ and poor for a small $\mu$, because the tremor amplitude is correlated with positive normal stress changes and less correlated with the shear stress changes (Fig. 4). The normal stress change as well as the

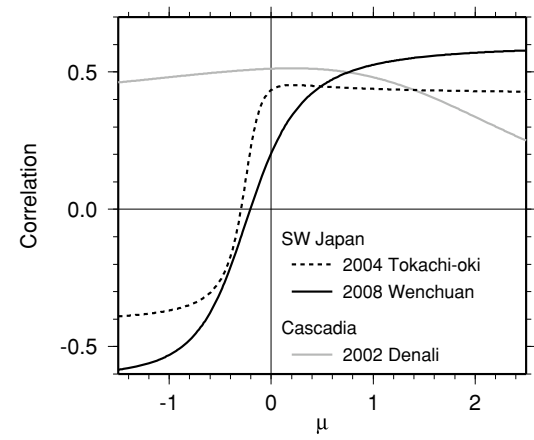

Fig. 5. Correlation between the triggered tremor amplitude and the Coulomb failure stress change in the source region, as a function of the apparent friction coefficient $(\mu)$. For southwest Japan, the cases of the 2004 Tokachi-oki earthquake and 2008 Wenchuan earthquake are shown. For the Cascadia region, the case of the 2002 Denali earthquake is shown, where the correlation is obtained by using the tremor and stress traces from Rubinstein et al. (2007). 


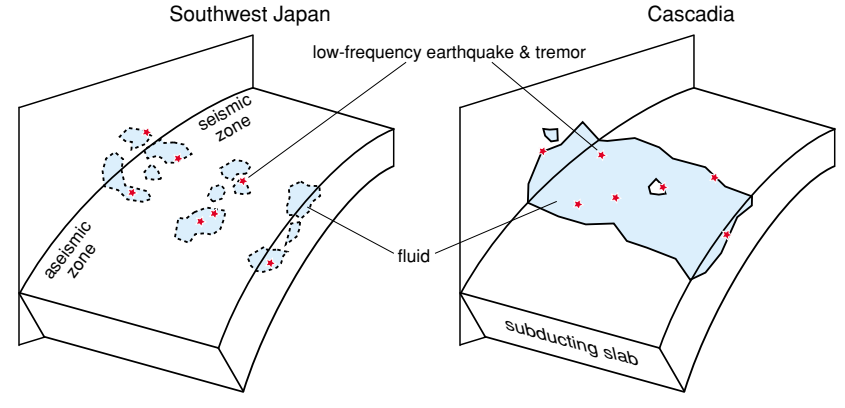

Fig. 6. Schematic illustrations of fluid distribution in southwest Japan and the Cascadia subduction zones.

Coulomb failure stress change with a large friction coefficient is largely responsible for the triggering. For the 2003 Tokachi-oki earthquake, the normal stress change and the shear stress change resolved on the fault plane incidentally have almost the same phase, then for $\mu>0$, the Coulomb failure stress change is also in the same phase and the correlation provides the similar value (see also figure 15 by Miyazawa and Brodsky, 2008). This makes it difficult to obtain the friction coefficient that provides the largest correlation and to distinguish which is responsible for the triggering, however the envelope amplitude of Rayleigh waves, rather than Love waves, correlates with the tremor amplitude (Fig. 1), despite large shear stress contribution from Love wave passage (Fig. 2). This indicates a preference for the correlation with the normal stress changes. For the 2007 Solomon earthquake, both normal and shear stress changes resolved on the fault are mostly from Rayleigh wave and there is less influence from Love wave due to the geometry (Fig. 2). This appears to be useful to examine if the shear stress from Rayleigh wave affects the triggering. However, the amplitude of triggered tremor is too small at other stations to obtain the location, and we could not examine the correlation. In the Cascadia region, it is quantitatively indicated that the relationship for the 2002 Denali earthquake contradicts to the results in southwest Japan and the shear stress change triggered the tremor.

We propose that the different behavior in different subduction zones is related to the amount of fluid in the source regions of the tremor (Fig. 6). Dehydration from young subducting slabs likely plays an important role for the tremor (Shelly et al., 2006; Nugraha and Mori, 2006) and nearby slow slip events (Kodaira et al., 2004). In southwest Japan, since the large friction coefficient and the normal stress change are responsible for the triggering, we speculate that the fault plane or the hypocenter is initially relatively dry, adjacent fluid migrates and diffuses into the fault or the source region under a subcritical condition with the volume strain changes produced by the Rayleigh waves, and the fluid reduces the fault strength. The triggering mechanism seems to be complicated depending on where and how the fluid exists. The fluid may heterogeneously exist on and off the fault plane. The fluid movement and diffusion may involve a very short migration distance because of the instant response appeared as tremor, which can be caused by the instant permeability change or the pore pressure difference (Miyazawa and Brodsky, 2008). The normal stress reduction accompanied with the horizontal com- pression is also required to effectively excite the rupture. In the Cascadia subduction zone, the fault plane is almost uniformly fluid rich, where the fluid movement due to volume strain change does not happen, and responds directly to shear strain changes. Furthermore, subduction zones, such as in northeast Japan where no low-frequency tremor has been observed, are inferred to be even more fluid poor than in southwest Japan.

Acknowledgments. We use Hi-net and F-net data provided by National Research Institute for Earth Science and Disaster Prevention (NIED) and hypocenters from the JMA catalogue. Discussion with Justin L. Rubinstein helped develop this study. We thank David P. Hill and an anonymous reviewer for careful and thoughtful reviews. This study was supported by Grant-in-Aid for Young Scientists (B) 19740275, MEXT, Japan.

\section{References}

Hill, D. P., Dynamic stresses, Coulomb failure, and remote triggering, Bull. Seismol. Soc. Am., 98, 66-92, 2008.

Hirose, H. and K. Obara, Repeating short- and long-term slow slip events with deep tremor activity around the Bungo channel region, southwest Japan, Earth Planets Space, 57, 961-972, 2005.

Ide, S., D. R. Shelly, and G. C. Beroza, Mechanism of deep low frequency earthquakes: Further evidence that deep non-volcanic tremor is generated by shear slip on the plate interface, Geophys. Res. Lett., 34, L03308, 2007.

Kao, H., S.-J. Shan, H. Dragert, G. Rogers, J. F. Cassidy, K. Wang, T. S. James, and K. Ramachandran, Spatial-temporal patterns of seismic tremors in northern Cascadia, J. Geophys. Res., 111, B03309, 2006.

Kodaira, S., T. Iidaka, A. Kato, J.-O. Park, T. Iwasaki, and Y. Kaneda, High pore fluid pressure may cause silent slip in the Nankai trough, Science, 304, 1295-1298, 2004.

Miyazawa, M. and J. Mori, Detection of triggered deep low-frequency events from the 2003 Tokachi-oki earthquake, Geophys. Res. Lett., 32, L10307, 2005.

Miyazawa, M. and J. Mori, Evidence suggesting fluid flow beneath Japan due to periodic seismic triggering from the 2004 Sumatra-Andaman earthquake, Geophys. Res. Lett., 33, L05303, 2006.

Miyazawa, M. and E. E. Brodsky, Deep low-frequency tremor that correlates with passing surface waves, J. Geophys. Res., 113, B01307, 2008.

Nakata, R., N. Suda, and H. Tsuruoka, Non-volcanic tremor resulting from the combined effect of Earth tides and slow slip events, Nature Geosci., 1, 676-678, 2008.

Nugraha, A. D. and J. Mori, 3-D velocity structure in the Bungo channel and Shikoku Area, Japan, and its relationship to low-frequency earthquakes, Geophys. Res. Lett., 33, L24307, 2006.

Obara, K., Nonvolcanic deep tremor associated with subduction in southwest Japan, Science, 296, 1679-1681, 2002.

Obara, K., Time sequence of deep low-frequency tremors in the southwest Japan subduction zone: Triggering phenomena and periodic activity, $J$. Geogr., 112, 837-849, 2003 (in Japanese with English abstract).

Rogers, G. and H. Dragert, Episodic tremor and slip on Cascadia subduction zone: The chatter of silent slip, Science, 300, 1942-1943, 2003.

Rubinstein, J. L., J. E. Vidale, J. Gomberg, P. Bodin, K. C. Creager, and S. D. Malone, Non-volcanic tremor driven by large transient shear stresses, Nature, 448, 579-582, 2007.

Rubinstein, J. L., J. Gomberg, J. E. Vidale, A. G. Wech, H. Kao, K. C. Creager, and G. Rogers, Dynamic triggering of non-volcanic tremor, ETS and earthquakes on Vancouver Island, J. Geophys. Res., 2008a (submitted).

Rubinstein, J. L., M. La Rocca, J. E. Vidale, K. C. Creager, and A. G. Wech, Tidal modulation of nonvolcanic tremor, Science, 319, 186-189, 2008b.

Schwartz, S. Y. and J. M. Rokosky, Slow slip events and seismic tremor at circum-Pacific subduction zones, Rev. Geophys., 45, RG3004, 2007.

Shelly, D. R., G. C. Beroza, S. Ide, and S. Nakamula, Low-frequency earthquakes in Shikoku, Japan, and their relationship to episodic tremor and slip, Nature, 442, 188-191, 2006.

M. Miyazawa (e-mail: linen@eqh.dpri.kyoto-u.ac.jp), E. E. Brodsky, and J. Mori 